\title{
Effect of feeding on ventilation and respiratory mechanics in newborn infants
}

\author{
VICTOR Y. H. YU and PETER ROLFE \\ From the Department of Paediatrics, John Radcliffe Hospital, Oxford
}

\begin{abstract}
Yu, V. Y. H., and Rolfe, P. (1976). Archives of Disease in Childhood, 51, 310. Effect of feeding on ventilation and respiratory mechanics in newborn infants. Measurements of ventilation and respiratory mechanics were made before and after tube feeding in 24 infants. In 12 infants with the respiratory distress syndrome tidal volume tended to fall after feeding; as the respiratory rate increased after feeding, minute ventilation remained unchanged. Hypoventilation is therefore unlikely to be the cause of hypoxaemia after feeding. Compliance, resistance, and the work of breathing showed no changes after feeding. In 12 healthy infants feeding had no effects on pulmonary function. There was a slight rise in compliance and a tendency for work of breathing to fall after feeding. Respiratory rate, tidal volume, and minute ventilation remained unchanged. There was therefore no evidence of adverse effects of feeding on any of the factors measured. It is suggested that hypoxaemia without hypoventilation after feeding in infants with pre-existing respiratory distress syndrome might be attributable to a reduction in functional residual capacity associated with a greater extent of airways closure than before feeding.
\end{abstract}

The metabolic advantage of immediate and adequate feeding of low birthweight infants has been established (Smallpeice and Davies, 1964). Whether feeding causes such infants any respiratory embarrassment, however, remains controversial. In most studies of pulmonary function in the newborn infant, no attempt has been made to relate the results to feeding. Barrie (1968) has described increased intraoesophageal swings after tube feeding. Russell and Feather (1970) showed that small bottle feeds had no harmful effect on the respiratory mechanics of healthy term infants. Previous investigations have not included infants with respiratory distress requiring tube feeding, in whom ventilation or respiratory mechanics might be affected more consistently or adversely. Impaired arterial oxygenation has been shown after feeding in such ill newborn infants (Klein, Harrison, and Heese, 1973; Wilkinson and Yu, 1974). A technique for the study of neonatal pulmonary function is described and thc effects of feeding infants suffering from the respiratory distress syndrome and healthy control infants are reported.

Received 31 July 1975.

\section{Material and methods}

Twelve ill newborn infants suffering from the respiratory distress syndrome, the presumptive cause of which was hyaline membrane disease, and 12 healthy control infants with no respiratory difficulty were studied (Table I). The control infants were admitted

TABLE I

\begin{tabular}{l|c|c}
\multicolumn{2}{c}{ Clinical data of infants studied } & (mean $\pm S E M)$ \\
\hline & $\begin{array}{c}\text { Infants with } \\
\text { respiratory distress } \\
\text { syndrome }\end{array}$ & $\begin{array}{c}\text { Healthy } \\
\text { control infants }\end{array}$ \\
\hline Birthweight (g) & $2548 \pm 96$ & $2555 \pm 229$ \\
Gestation (w) & $36 \pm 0.5$ & $37 \pm 0 \cdot 7$ \\
Postnatal age (h) & $15 \pm 2 \cdot 3$ & $14 \pm 1.7$ \\
Ambient oxygen & $41 \pm 2 \cdot 2$ & 21 (room air) \\
$\begin{array}{c}\text { (\%) } \\
\text { Duration of feed } \\
\text { (min) }\end{array}$ & $6 \pm 0.5$ & $5 \pm 0.4$ \\
\hline
\end{tabular}

to the special care baby unit either because they were preterm and/or small-for-dates, or in the case of the bigger infants because of intrapartum asphyxia from which they recovered promptly, subsequently proving to be normal infants. No significant differences were present in birthweight or gestational age in the two groups. The ambient oxygen concentration at the time of study in the ill infants ranged from $30-50 \%$ (mean 
$41 \%$ ). The healthy control infants were all breathing room air. Postnatal age at the time of study ranged from 5-27 hours. All were given milk $5 \mathrm{ml} / \mathrm{kg}$ per feed. With the exception of 3, all the ill infants received human milk, but 8 of the healthy controls were on cow's milk formula. Tube feeding was given via an orogastric tube. No difference was present for the duration of the tube feeds given by the gravity method in the two groups of infants studied.

A pneumotachograph with an adaptor for measurements during spontaneous nasal breathing was used. The nasal adaptor fitted into the infant's anterior nares in a manner similar to the valve by Golinko and Rudolph (1961). To reduce discomfort and prevent leakage, the adaptors were coated with $5 \%$ Xylocaine ointment as described by Rigatto and Brady (1972). The pneumotachograph was connected to an Elema Schoenander differential pressure transducer (type EMT). The relation between the pressure drop across the screen and air flow was shown to be linear at flow rates of up to $150 \mathrm{ml} / \mathrm{s}$. The output from the transducer was integrated electrically to obtain a display of tidal volume on a polygraph (type M19 recorder, Devices, London) simultaneously with the tidal flow recording. The dead space of the pneumotachograph was $1.8 \mathrm{ml}$ and it had a low resistance of $1.6 \mathrm{~cm} \mathrm{H}_{2} \mathrm{O} / 1$ per second. Calibrations were carried out immediately after each study using a gas mixture of the same temperature and composition as that inspired by the infant during the study.

Oesophageal pressure was measured with a latex balloon sealed over the tip of a no. 5 French gauge polyvinyl feeding tube attached to a pressure transducer (Bell and Howell, type 4-442, Basingstoke, England). Calibration of the transducer was carried out with a water manometer immediately after each study.

Respiratory rate was counted from the tidal volume recording over one minute. Minute ventilation was obtained from summation of the tidal volumes in the same minute. The average tidal volume was calculated by dividing the minute ventilation by the respiratory rate. For the purpose of calculating compliance and resistance, 10 consecutive breaths during a period of steady breathing were used. The method was similar to that described by Cook et al. (1957). Dynamic compliance was calculated by dividing the tidal volume by the change in oesophageal pressure at the points of zero air flow. Respiratory resistance was calculated by dividing the total pressure change, between points of equal volume midway in inspiration and expiration, by the corresponding total respiratory air flow change. The total mechanical work of breathing over one minute was calculated with the formula of Otis, Fenn, and Rahn (1949/50). Simultaneous pressure volume diagrams in suitable cases, free from artefacts in the tracing, have confirmed the close agreement between diagrammatic and formula calculations of mechanical work previously shown by Cook et al. (1957) in newborn infants. The formula used was: work (in $\mathrm{cm} / \mathrm{min}$ ) = $\frac{1}{2} \mathrm{f} \mathrm{Kel}(\mathrm{Vt})^{2}+\frac{1}{\mathrm{~K}} \mathrm{Kr}^{2} \mathrm{f}^{2}(\mathrm{Vt})^{2}$, where $\mathrm{Kel}$ is compliance ${ }^{-1}$ with compliance expressed as $\mathrm{ml} / \mathrm{cm} \mathrm{H}_{2} \mathrm{O}$; Vt is tidal volume in $\mathrm{ml}$; $\mathrm{f}$ is breaths/min; $\mathrm{Kr}$ is resistance in $\mathrm{cm}$ $\mathrm{H}_{2} \mathrm{O} / \mathrm{ml}$ per minute.

The nasal adaptor and the oesophageal balloon were positioned 30 minutes before the feed was scheduled. The pneumotachograph was attached and tracings of tidal flow, tidal volume, and oesophageal pressure obtained and scrutinized for technical errors or artefacts. The pneumotachograph was then removed and the infant left undisturbed until immediately before the feed. The pneumotachograph was again attached and further recordings were made (prefeed study). With the nasal adaptor but not the pneumotachograph in situ, the infant was given the tube feed, after which further recordings were made (postfeed study). The interval between the prefeed and postfeed studies ranged from 12-25 minutes (mean 20 minutes). The nursing of the infant and therefore the studies were carried out in the supine position.

\section{Results}

Student's ' $t$ ' test for pairs was used to evaluate the differences between the results of the prefeed and postfeed studies. Table II shows the results

\section{TABLE II}

Measurements of ventilation and respiratory mechanics before and after feeding in infants with respiratory distress (mean $\pm S E M$ )

\begin{tabular}{|c|c|c|}
\hline & Before feed & After feed \\
\hline $\begin{array}{l}\text { Respiratory rate } \\
\text { (min) } \\
\text { Tidal volume (ml) } \\
\text { (ml/kg) } \\
\text { Minute ventilation } \\
\text { (ml) } \\
\text { (ml/kg) } \\
\text { Compliance } \\
\left(\mathrm{ml} / \mathrm{cmH}_{2} \mathrm{O}\right) \\
\left(\mathrm{ml} / \mathrm{cmH}_{2} \mathrm{O} \text { per } \mathrm{kg}\right) \\
\text { Resistance } \\
\text { (cmH } \mathrm{m}_{2} \mathrm{O} / 1 \text { per s) } \\
\text { Work }(\mathrm{gm} \mathrm{cm} / \mathrm{min}) \\
\text { (gm } \mathrm{cm} / \mathrm{min} \text { per } \mathrm{kg})\end{array}$ & $\begin{array}{c}68 \pm 2 \cdot 9 \\
12 \cdot 6 \pm 1 \cdot 0 \\
4 \pm \cdot 90 \cdot 2 \\
854 \pm 77 \\
331 \pm 23 \\
1 \cdot 1 \pm 0 \cdot 1 \\
0 \cdot 42 \pm 0 \cdot 03 \\
40 \pm 4 \cdot 4 \\
6951 \pm 1053 \\
2674 \pm 391\end{array}$ & $\begin{array}{c}77 \pm 2 \cdot 9 \star \\
11 \cdot 3 \pm 1 \cdot 0 \dagger \\
4 \cdot 4 \pm 0 \cdot 3 \dagger \\
864 \pm 77 \\
336 \pm 24 \\
1 \cdot 0 \pm 0 \cdot 1 \\
0 \cdot 41 \pm 0 \cdot 03 \\
43 \pm 5 \cdot 3 \\
6900 \pm 1045 \\
2668 \pm 378\end{array}$ \\
\hline
\end{tabular}

Compared with prefeed values: ${ }^{\star} \mathrm{P}<0.001 ;+0.05<P<0.1$.

of mean $\pm S E M$ values for respiratory rate, tidal volume, minute ventilation, compliance, resistance, and work of breathing before and after feeding in infants with respiratory distress. All values except respiratory rate and resistance are expressed in their absolute values as well as per unit of bodyweight. Respiratory rate increased after feeding $(P<0 \cdot 001)$. Minute ventilation remained unchanged and thus there was a fall in tidal volume which, however, did not reach significance $(0 \cdot 05<\mathrm{P}<0 \cdot 1)$. No change in compliance was observed but respiratory resistance tended to increase after feeding though this change did not reach significance. The work of breathing showed no significant change. 
Table III shows the result of mean \pm SEM values for respiratory rate, tidal volume, minute ventilation, compliance, resistance, and work of breathing before and after feeding in healthy infants. Respiratory rate, tidal volume, and minute ventilation did not change. Mean compliance tended to increase after feeding but this change did not reach significance $(0.05<P<0.1)$. Total respiratory resistance remained unchanged and there was a tendency for work of breathing to fall after feeding.

\section{TABLE III}

Measurements of ventilation and respiratory mechanics before and after feeding in healthy infants (mean $\pm S E M)$

\begin{tabular}{|c|c|c|}
\hline & Before feed & After feed \\
\hline $\begin{array}{l}\text { Respiratory rate } \\
\text { (min) } \\
\text { Tidal volume (ml) } \\
\text { (ml/kg) } \\
\text { Minute ventilation } \\
\text { (ml) } \\
\text { (ml/kg) } \\
\text { Compliance } \\
\left.\text { (ml/cmH }{ }_{2} \mathrm{O}\right) \\
\quad\left(\mathrm{ml} / \mathrm{cmH}_{2} \mathrm{O} \text { per } \mathrm{kg}\right) \\
\text { Resistance } \\
\quad\left(\mathrm{cmH} \mathrm{H}_{2} \mathrm{O} / 1 \text { per s) }\right. \\
\text { Work } \\
\quad(\mathrm{gm} \mathrm{cm} / \mathrm{min}) \\
(\mathrm{gm} \mathrm{cm} / \mathrm{min} \text { per } \mathrm{kg})\end{array}$ & $\begin{aligned} 45 & \pm 2 \cdot 5 \\
15 \cdot 1 & \pm 1 \cdot 6 \\
5 \cdot 9 & \pm 0 \cdot 2 \\
646 & \pm 58 \\
259 & \pm 16 \\
& \\
4 \cdot 1 & \pm 0 \cdot 4 \\
1 \cdot 65 & \pm 0 \cdot 16 \\
44 & \pm 5 \cdot 2 \\
2083 & \pm 314 \\
918 & \pm 148\end{aligned}$ & $\begin{array}{c}46 \pm 2 \cdot 4 \\
14 \cdot 8 \pm 1 \cdot 6 \\
5 \cdot 8 \pm 0 \cdot 3 \\
644 \pm 50 \\
263 \pm 21 \\
4 \cdot 5 \pm 0 \cdot 4^{\star} \\
1 \cdot 79 \pm 0 \cdot 14^{\star} \\
43 \pm 5 \cdot 3 \\
1958 \pm 329 \\
819 \pm 170\end{array}$ \\
\hline
\end{tabular}

Compared with prefeed values: $\star_{0} \cdot 05<\mathrm{P}<0 \cdot 1$.

\section{Discussion}

Pulmonary function was measured at rest and after feeds in infants suffering from the respiratory distress syndrome and in healthy infants. Results in the group of apparently healthy infants were in keeping with the findings of previous investigators on low birthweight infants (Chu et al., 1967, Feather and Russell 1974) and in larger infants (Cook et al., 1957; Swyer, Reiman, and Wright, 1960). In infants with respiratory distress, the respiratory rate was raised, tidal volume decreased, and minute ventilation increased. Compliance was reduced to one-quarter the normal value. Resistance was essentially unchanged, but the decrease in compliance contributed to a greatly increased work of breathing. These findings were similar to those reported previously (Karlberg et al., 1954; Prod'hom et al., 1965; Chu et al., 1967; Avery and Fletcher, 1974).

From the time of Keith (1909), a number of authors have speculated on the effects of the abdominal body wall and the abdominal contents on the mechanics of respiration (Bancroft, 1955; Brody, Connolly, and Wander, 1959). Studies which contributed to the understanding of the problem were originally related to interests in the rocking method of artificial ventilation in adults (Colville, Shugg, and Ferris, 1956) and in newborn infants (Avery and O'Doherty, 1962). Differences in the mechanics of breathing with different positions in adults have also been attributed to pressure effect from the abdominal viscera (Blair and Hickham, 1955; Attinger, Monroe, and Segal, 1956). In addition to the hazards of inhalation, it has been traditionally held that early feeding of low birthweight infants led to respiratory difficulty from mechanical causes (Corner, 1962). The present study was undertaken to determine the influence of feeding on ventilatory function and respiratory mechanics.

The effect of bottle feeding on respiratory mechanics of healthy term infants has been studied (Russell and Feather, 1970). No significant changes were reported with respiratory rate, minute volume, pulmonary compliance, and the work of breathing after feeding. Similar results were obtained in the present study with tube feeding in the control group which consisted of both term and preterm infants. Though the changes were not significant, there was a slight rise in compliance and a tendency for work of breathing to fall after feeding. Feather and Russell (1974) reported an increase in compliance after bottle feeding in healthy low birthweight infants. They suggested that this change might be due to a decrease in pulmonary blood flow. In the same study mean work rate tended to fall after feeding in low birthweight infants of appropriate weight for gestation but to increase in small-for-dates infants. There was no evidence of any harmful effect of feeding on the respiratory mechanics of these infants.

In the group of infants with pre-existing respiratory distress, mean tidal volume tended to fall after feeding. As there was a significant increase in respiratory rate after feeding, minutc ventilation remained essentially unchanged. This finding is consistent with data on arterial carbon dioxide tension (Wilkinson and $\mathrm{Yu}, 1974$ ) which indicated that alveolar ventilation was not reduced after feeding.

Sufficient evidence was not found within the scope of the present study to explain the mechanism of hypoxaemia after feeding in newborn infants with respiratory distress; however, it seems unlikely that the basis of the disturbance lies in restriction of ventilation. McHardy and Simpson (1974) have suggested that, after feeding, expiratory 
reserve volume might be diminished and the already proportionately large closing volume might have intruded into the infants' tidal volume with resultant hypoxaemia. Small-airways calibre is related to transpulmonary pressure. Agostoni, D'Angelo, and Bonanni (1969/70) indicated that the vertical gradient of transpulmonary pressure in the horizontal position is markedly affected by the vertical gradient of abdominal pressure. In a small newborn infant the volume of feed is proportionately large in comparison with the volume of the abdominal contents. The hypothesis is that the reduction in functional residual capacity after feeding is associated with a raised transpulmonary pressure which causes airways closure, either de novo or to a greater extent than before feeding. At the present time, methods for direct measurement closing volume (Anthonisen et al., 1969/70; Mansell, Bryan, and Levison, 1972) cannot be applied to the newborn infant. It may be possible in future to make the appropriate measurements to indicate whether such mechanisms as suggested are indeed operating.

We are grateful to Professor J. P. M. Tizard for his help in the preparation of this paper.

\section{REPERENCES}

Agostoni, E., D'Angelo, E., and Bonanni, M. V. (1969/70). The effect of the abdomen on the vertical gradient of pleural surface pressure. Respiration Physiology, 8, 332.

Anthonisen, N. R., Danson, J., Robertson, P. C., and Ross, W. R. D. (1969/70). Airway closure as a function of age. Respiration Physiology, 8, 58.

Attinger, E. O., Monroe, R. G., and Segal, M. S. (1956). The mechanics of breathing in different body positions. Fournal of Clinical Investigation, 35, 904.

Avery, M. E., and Fletcher, B. D. (1974). The lung and its disorders in the newborn infant, 3rd ed., p. 211. Saunders, Philadelphia.

Avery, M. E., and O'Doherty, N. (1962). Effects of body-tilting on the resting end-expiratory position of newborn infants. Pediatrics, 29, 255.

Bancroft, R. W. (1955). Report No. 55. U.S.A.F. School of Aviation Medicine, Texas.

Barrie, H. (1968). Effect of feeding on gastric and oesophageal pressures in the newborn. Lancet, 2,1158 .
Blair, E., and Hickam, J. B. (1955). The effect of change in body position on lung vol ume and intrapulmonary gas mixing in normal subjects. fournal of Clinical Investigation, 34, 383.

Brody, A. W., Connolly, J. J., and Wander, H. J. (1959). Influence of abdominal muscles, mesenteric viscera and liver on respiratory mechanics. Fournal of Applied Physiology, 14, 121.

Chu, J., Clements, J. A., Cotton, E. K., Klaus, M. H., Sweet, A. Y., and Tooley, W. H. (1967). Neonatal pulmonary ischemia. Part I: clinical and physiological studies. Pediatrics, 40, 709.

Colville, P., Shugg, C., and Ferris, B. G., Jr. (1956). Effects of body tilting on respiratory mechanics. fournal of Applied Physiology, 9, 19.

Cook, C. D., Sutherland, J. M., Segal, S., Cherry, R. B., Mead, J., McIlroy, M. B., and Smith, C. A. (1957). Studies of respiratory physiology in the newborn infant. III. Measurements of mechanics of respiration. fournal of Clinical Investigation, 36,440 .

Corner, B. D. (1962). The premature infant's diet. Lancet, 1, 321.

Feather, E., and Russell, G. (1974). Respiratory mechanics in infants of low birth weight and the effects of feeding. Biology of the Neonate, 24, 117.

Golinko, R. J., and Rudolph, A. M. (1961). A valve for respiratory studies in infants. Pediatrics, 27, 645.

Karlberg, P., Cook, C. D., O'Brien, D., Cherry, R. B., and Smith, C. A. (1954). Studies of respiratory physiology in the newborn infant. II. Observations during and after respiratory distress. Acta Paediatrica, 43, Suppl. 100, 397.

Keith, A. (1909). Further Advances in Physiology. McGraw-Hill, London.

Klein, M., Harrison, V. C., and Heese, H. de V. (1973). Impaired arterial oxygenation after feeding in newborn infants. (Abstract.) Pediatric Research, 7, 398.

Mansell, A., Bryan, C., and Levison, H. (1972). Airway closure in children. Fournal of Applied Physiology, 33, 711.

McHardy, G. J. R., and Simpson, H. (1974). Effects of feeding on blood-gases in a newborn infant. Lancet, $2,352$.

Otis, A. B., Fenn, W. O., and Rahn, H. (1949/50). Mechanics of breathing in man. Fournal of Applied Physiology, 2, 592.

Prod'hom, L. S., Levison, H., Cherry, R. B., and Smith, C. A. (1965). Adjustment of ventilation, intrapulmonary gas exchange, and acid-base balance during the first day of life. Infants with early respiratory distress. Pediatrics, 35, 662 .

Rigatto, H., and Brady, J. P. (1972). A new nosepiece for measuring ventilation in preterm infants. Fournal of Applied Physiology, 32, 423.

Russell, G., and Feather, E. A. (1970). Effects of feeding on respiratory mechanics of healthy newborn infants. Archives of Disease in Childhood, 45, 325.

Smallpeice, B., and Davies, P. A. (1964). Immediate feeding of premature infants with undiluted breast-milk. Lancet, 2, 1349.

Swyer, P. R., Reiman, R. C., and Wright, J. J. (1960). Ventilation and ventilatory mechanics in the newborn. Fournal of Pediatrics, 56, 612.

Wilkinson, A., and Yu, V. Y. H. (1974). Immediate effects of feeding on blood-gases and some cardiorespiratory functions in ill newborn infants. Lancet, 1, 1083.

Correspondence to Dr. V. Y. H. Yu, Department of Paediatrics, McMaster University Medical Centre, Hamilton, Ontario, Canada L8S 4J9. 